\title{
Internal resorption
}

\author{
Ravi Prakash Sasankoti Mohan, ${ }^{1}$ Sankalp Verma, ${ }^{2}$ Udita Singh, ${ }^{2}$ Neha Agarwal ${ }^{2}$
}

${ }^{1}$ Department of OMDR, Kothiwal Dental College, Moradabad, Uttar Pradesh, India

${ }^{2}$ Depatrment of Oral Medicine and Radiology, Kothiwal Dental College \& Research Center, Moradabad, Uttar Pradesh, India

\section{Correspondence to}

Dr Ravi Prakash Sasankoti Mohan,

sasan_ravi@rediffmail.com

\section{SUMMARY}

Internal resorption is a relatively rare resorption of dentine, which starts in the pulpal cavity either in the pulpal chamber or in the root canal and destroys surrounding dental hard tissues. The initiating factor in internal root resorption is thought to be trauma or chronic pulpal inflammation, but other aetiological factors have also been suggested. The prognosis for treatment of small lesions of internal resorption is good. However, if the tooth structure is greatly weakened and perforation has occurred, the prognosis is poor and tooth extraction must be considered. In this article we report a rare case of internal resorption in a 26-year-old male patient.

\section{BACKGROUND}

The internal resorption is also called intracanal resorption. It is considered as a rare case of resorption which appears as a typical dystrophy of the pulp which jeopardises the hard tissue of the teeth, thus changing its normal morphology. ${ }^{1}$ Root resorption is the loss of dental hard tissues as a result of clastic activities. It might occur as a physiological or pathological phenomenon. Root resorption in the primary dentition is a normal physiological process except when the resorption occurs prematurely. The initiating factors involved in physiological root resorption in the primary dentition are not completely understood, although the process appears to be regulated by cytokines and transcription factors that are similar to those involved in bone remodelling. ${ }^{2}$ Unlike bone that undergoes continuous physiological remodelling throughout life, root resorption of permanent teeth does not occur naturally and is invariably inflammatory in nature. Thus, root resorption in the permanent dentition is a pathological event; if untreated, this might result in the premature loss of the affected teeth. ${ }^{2}{ }^{3}$ It is caused by transformation of normal pulp tissue into granulomatous tissue with giant cells, which resorb dentine. Trauma, caries and restorative procedures have been suggested to be contributing factors, but it also occurs as an idiopathic dystrophic changes. ${ }^{4} 5$ Most cases of internal resorption are asymptomatic and often detected as an incidental radiographic finding. ${ }^{5} 6$ When internal resorption is detected, root canal therapy is the only effective treatment and should begin as soon as possible to limit progression. ${ }^{6}$

\section{CASE PRESENTATION}

A 26-year-old male patient reported to our department with a history of continuous throbbing pain and extraoral swelling in relation to maxillary central incisor for the past 2 days. The patient gave a history of orthodontic treatment for the correction of proclined anterior teeth started 6 years ago which was discontinued 4 years hence as he presented with pain in the central incisor. The patient discontinued the previous endodontic treatment and reported 10 months later with pain and swelling. There was no relevant medical history. On clinical examination the maxillary central incisor revealed small defect on the labial surface of the tooth with no obvious discolouration (figure 1) and it had palatal access cavity prepared from the previous endodontic treatment and dislodged restoration, the tooth was found to be non-vital, gingival sulcus depth was normal, the tooth was slightly mobile due to the presence of dentoalveolar abscess.

\section{INVESTIGATIONS}

Intraoral periapical radiograph of the tooth revealed large radiolucent lesion completely involving the pulp chamber, along with perforation of the lingual wall (figure 2).

\section{DIFFERENTIAL DIAGNOSIS \\ External root resorption}

- Resorption of coronal dentine and enamel often creates a clinically obvious pinkish colour in the tooth crown as highly vascular resorptive tissue becomes visible through thin residual enamel (cervical resorption).

- When tooth structure is replaced with bone that fuses with dentine, it is termed replacement resorption or ankylosis.

Radiographically:

- The border will be irregular and ill defined.

- If the lesion is superimposed on the root canal system, it should be possible to follow the canal walls unaltered through the area of defect.

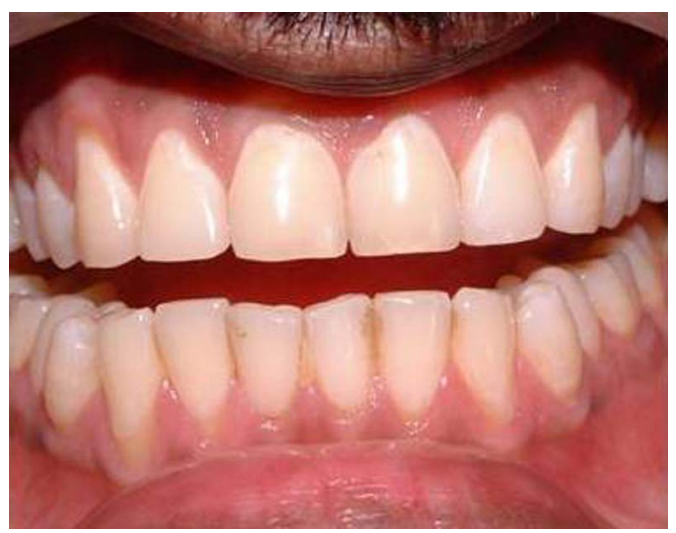

Figure 1 Intraoral examination of maxillary central incisor revealed small defect on the labial surface of the tooth with no obvious discolouration. 


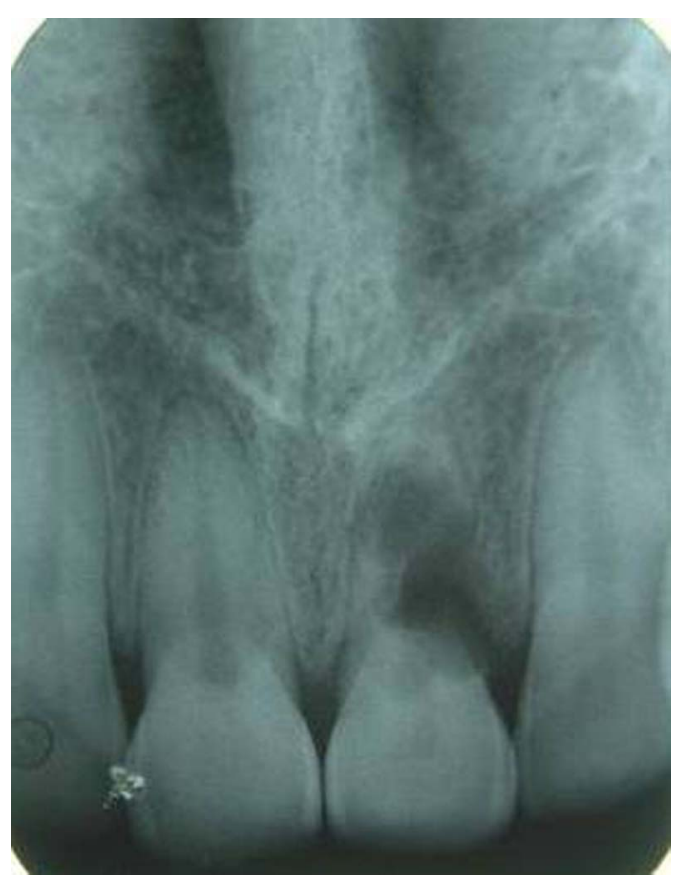

Figure 2 Intraoral periapical radiograph of the tooth revealed a large radiolucent lesion completely involving the pulp chamber, along with perforation of the lingual wall.

- Their distribution is not symmetrical and can occur on any root surface.

- Their may be variations in the radiodensity of the body of lesion.

- Lesion shift on changing angulations.

\section{TREATMENT}

In the present case, the patient was referred to the department of oral and maxillofacial surgery for extraction of the affected tooth (figure 3).

\section{OUTCOME AND FOLLOW-UP}

The prognosis for the current case was good.

\section{DISCUSSION}

Internal resorption is considered to be an inflammatory process established by the association between a pulp aggression, which

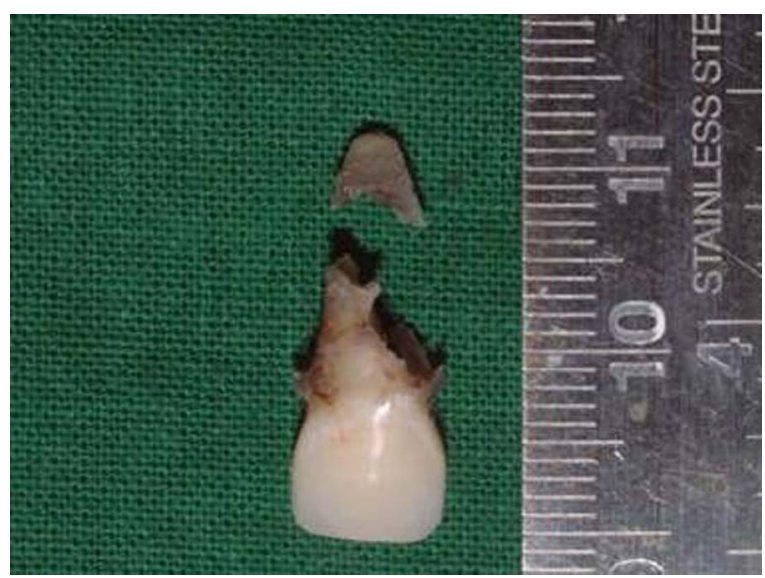

Figure 3 Extracted upper left central incisor showing resorption of root portion at the middle third of the tooth. causes a focal necrosis of the odontoblasts and a chronic inflammatory process without pulp necrosis. ${ }^{7}$ Internal resorptions happen in the surface of the dentine walls that form the pulp cavity and are not as frequent as the external ones. ${ }^{467}$ Internal resorption is defined as an idiopathic slow or fast progressive resorptive process occurring in the dentine of the pulp chamber or root canals of teeth. ${ }^{8}$ Internal resorption may affect any tooth in either the primary or secondary dentition, but it is more frequently observed in permanent teeth. ${ }^{6}$ In present case also it is observed in permanent teeth. It occurs most often during the fourth and fifth decades and in men. Most cases of internal resorption are seen in anterior teeth. ${ }^{6}$

These findings were also evident in the present case. Resorption of calcified dental tissue involves demineralisation due to reversal of the cation exchange and lacunar resorption by osteoclasts. The resorptive process can progress at different speeds and with different periods of activity. ${ }^{2}{ }^{4}$ Two main patterns are seen: (1) inflammatory resorption and (2) replacement or metaplastic absorption. In inflammatory resorption, the resorbed dentine is replaced by inflamed granulation tissue. Although this pattern may involve any portion of the canal, the cervical zone is affected most frequently (pulp inflammation is usually caused by bacterial invasion). ${ }^{2}{ }^{4-6}$ The resorption continues as long as vital pulp remains; typically, the coronal pulp is necrotic with the apical portion remaining vital. The results of pulp testing are variable. In this pattern the area of destruction usually appear as a uniform well-circumscribed symmetric radiolucent enlargement of the pulp chamber or canal. When it affect the coronal pulp, the crown can display a pink discolouration (pink tooth of Mummery, named after the anatomist 'James Howard Mummery') as the vascular resorptive process approaches the surface. When it occurs in the root, the original outline of the canal is lost and a balloon like radiographic dilation of the canal is seen. Although most cases are progressive, some cases are transient and arise in traumatised teeth or those that have recently undergone orthodontic or periodontal therapy. Internal root resorption (IRR) following orthodontic treatment is a rarely reported occurrence. Apical root resorption normally characterised by apical rounding is a common event in orthodontic treatment. IRR originating from inadequate caries removal and orthodontic treatment was reported. ${ }^{2}$ In the present case the patient did not give any history of traumatic injury but of orthodontic treatment and a discontinued endodontic treatment which could be the predisposing factors for IRR to occur. Its aetiology is not quite clarified, however, can be associated with dental traumatism and inflammatory alterations of dental pulp after pulp capping or pulpotomy. Kinomoto et al (2002) add that it can also happen due to the infection of dental pulp or extreme heat. These annoying facts stimulate the pulp tissue, thus the inflammatory process starts and then some undifferentiated cells of the pulp can convert themselves to osteoclasts or macrophages, which result in dentinal resorption. ${ }^{1}$ In the majority of the cases, the internal resorption usually is asymptomatic and detectable by routine radiographs (Gunraj and Washington, 1999; Esberard et al, 2002; Hsien et al, 2003). ${ }^{124}$ Histopathologically it is characterised by resorption of the internal aspect of the root due to the result of osteoclastic activity and the presence of lacunae which may be filled in by osteoid tissue, presence of multinucleated giant cells or dentinoclasts. The pulp is usually chronically inflamed and metaplasia of pulp may occur. ${ }^{8}$ Radiographically internal resorption appears as a uniform, round to oval radiolucent enlargement of the canal. If there is no perforation, it is not associated with the external surface of the tooth. ${ }^{6}$ In present case there is diffuse 
radiolucency present at the cervical and middle third of the root canal causing perforation of the lingual canal. Successful treatment requires proper diagnosis and a good history. Once internal resorption has been diagnosed, the clinician must make a decision on the prognosis of the tooth. It is important to know if the resorption is purely internal, initiating within the pulp chamber and not communicating with the periodontal ligament. If the resorptive area is communicating, then it is an internal external resorptive case, and the prognosis is questionable. If the tooth is deemed restorable and has a reasonable prognosis, root canal treatment is the treatment of choice. The aim of root canal treatment is to remove any vital and necrotic pulp that might be sustaining and stimulating the resorbing cells

\section{Learning points}

- Root canal treatment remains the only treatment of choice with teeth diagnosed with internal resorption.

- Early detection and a correct differential diagnosis are essential for successful management of the outcome of internal resorption to prevent over weakening of remaining tooth structure and root perforations.

- Because the resorptive defect is the result of an inflamed pulp and the clastic precursor cells are predominantly recruited through the blood vessels, controlling the process of internal root resorption is conceptually easy, via the blood supply to the resorbing tissues with conventional root canal therapy. via their blood supply and to disinfect and obturate the root canal system. Access cavity preparation should be conservative, preserving as much tooth structure as possible and should avoid further weakening of the already compromised tooth. Prognosis is good; however, the patient must be recalled, since the resorptive defect can recur. Once perforation occurs, therapy becomes more difficult and the prognosis is poor; in such cases repair must be carried out to create a barrier. Initial placement of calcium hydroxide paste occasionally may result in remineralisation of the site of perforation and stop the resorptive process. Extraction often is necessary for radicular perforation that does not respond to therapy. ${ }^{4}$

\section{Competing interests None.}

Patient consent Obtained.

Provenance and peer review Not commissioned; externally peer reviewed.

\section{REFERENCES}

1 Araujo LCG, Lins CV, Lima GA, et al. Study of prevalence of internal resorption in periapical radiography of anterior permanent teeth. Int J Morphol 2009;27:227-30.

2 Patel S, Dent MC, Ricucci D, et al. Internal root resorption: a review. J Endod 2010;36:1107-21.

3 Fernandes M, Ataide ID, Wagle R. Tooth resorption part 1-pathogenesis and case series of internal resorption. J Conservative Dent 2013;16:4-8.

4 Datana S, Radhakrishnan V. Internal resorption: an unusual form of tooth resorption. MJAFI 2011;67:364-6.

5 Maria R, Mantri V, Koolwal S. Internal resorption: A review and case report. Endodontology 2010;22:100-8.

6 Ozdabak N, Akgul N, Karaoglanoglu S, et al. Pink spot in internal resorption (a case report). J Dent Fac Ataturk Uni 2011;4:99-102.

7 Martos J, Silveira LFM, Souza JM, et al. Internal root resorption in the maxillary central incisor. Rev Sul-Bras Odontol 2010;7:239-43.

8 Mandke L, Kachalia K. Management of internal resorption-a case report. Sci J 2007;1:1-3.

Copyright 2013 BMJ Publishing Group. All rights reserved. For permission to reuse any of this content visit

http://group.bmj.com/group/rights-licensing/permissions.

BMJ Case Report Fellows may re-use this article for personal use and teaching without any further permission.

Become a Fellow of BMJ Case Reports today and you can:

- Submit as many cases as you like

- Enjoy fast sympathetic peer review and rapid publication of accepted articles

- Access all the published articles

- Re-use any of the published material for personal use and teaching without further permission

For information on Institutional Fellowships contact consortiasales@bmjgroup.com

Visit casereports.bmj.com for more articles like this and to become a Fellow 